\title{
Disponibilidade de energia líquida no leite e desempenho ponderal de bezerros Hereford e Aberdeen Angus do nascimento à desmama
}

\author{
Karine Maciel Forster ${ }^{1}$, Marcelo Alves Pimentel ${ }^{2}$, José Carlos Ferrugem Moraes $^{3}$
}

\author{
${ }^{1}$ Mestranda do Programa de Pós-graduação em Zootecnia - UFPEL/Pelotas. \\ 2 Departamento de Zootecnia - FAEM - UFPEL/Pelotas. \\ 3 EMBRAPA Pecuária Sul/Bagé.
}

RESUMO - Esta pesquisa foi realizada com o objetivo de avaliar o desempenho ponderal de bezerros do nascimento aos 189 dias de vida. Foram utilizados 95 bezerros (55 Aberdeen Angus e 40 Hereford) manejados em campo nativo. A produção de leite das vacas foi estimada pelo método pesagem-mamada-pesagem, e o desempenho ponderal dos bezerros foi avaliado em intervalos de 21 dias a partir do nascimento. A parição foi dividida em época 1 (setembro) e época 2 (outubro). Para análise foram incluídos no modelo estatístico como efeitos fixos a raça das vacas, o sexo dos bezerros à época de parição, a ordem de parto e a gestação. Os dados foram submetidos à análise estatística, adotando-se 0,5 como nível crítico de probabilidade. A raça das mães influenciou o peso dos bezerros ao desmame, o ganho médio diário e a eficiência das vacas com 191,90 e 163,02 kg; 0,78 e 0,64 kg; e 45,24 e 39,40\% para Aberdeen Angus e Hereford, respectivamente. Vacas multíparas superaram as primíparas nos pesos dos bezerros ao nascimento e ao desmame e no ganho médio diário. A época de nascimento afetou os pesos do bezerro ao nascimento e ao desmame, o ganho médio diário e a produção total de leite, cujos valores para setembro e outubro foram, respectivamente, 31,15 e $37,19 \mathrm{~kg} ; 183,63$ e $171,29 \mathrm{~kg} ; 0,76$ e 0,67 kg; e, 1605,04 e 1378,78 kg. Setembro foi o melhor período para peso do bezerro ao desmame, ganho médio diário e produção total de leite, enquanto outubro foi melhor apenas para o peso do bezerro ao nascimento. O desempenho dos bezerros não é influenciado pelo sexos nem pela prenhez da vaca.

Palavras-chave: bovinos de corte, ganho de peso, lactação, mantença, produção

\section{Availability of net energy in the milk and weight performance in Hereford and Aberdeen Angus calves from birth to weaning}

\begin{abstract}
This research aimed at evaluating ponderal performance of the calves from birth to 189 days of age. Ninety-five calves were used (55 Aberdeen Angus and 40 Hereford), grazing natural pasture. Milk production of cows was estimated by the weight-suckled-weight method, and ponderal performance of the calves was evaluated in 21-day intervals from birth. Calving season was divided at time 1 (September) and time 2 (October). For analyses, it was included in the statistical model as fixed effects, breed of the cows, calf sex in the calving season, calving order and pregnancy. Data were submitted to statistical analyses, adopting 0.5 as critical levels of probability. Breed of the dams influenced calves weaning weight, average daily weight gain and cow efficiency, with 191.90 and $163.02 \mathrm{~kg}, 0.78$ and $0.64 \mathrm{~kg}$, and, 45.24 and $39.40 \%$, for Aberdeen Angus and Hereford, respectively. Multiparous cows were superior to primiparous on weight of the calves on birth and on weaning on average daily weight gain. Calving season affected weights of the calves on birth and on weaning, average daily weight gain and total milk production with the following values for September and October: 31.15 and $37.19 \mathrm{~kg}$; 183.63 and $171.29 \mathrm{~kg} ; 0.76$ and $0.67 \mathrm{~kg}$; and, $1,605.04$ and $1,378.78 \mathrm{~kg}$, respectively. September was the best time for calf weight at weaning, average daily weight gain and total milk production, while October was better only for birth weight. Performance of calves is not influenced by their sex neither by pregnancy.
\end{abstract}

Key Words: beef cattle, lactation, maintaining, yield, weight gain

\section{Introdução}

Durante as primeiras semanas de vida, o leite materno é essencial para a sobrevivência dos bezerros, que nessa fase têm uma dieta exclusivamente líquida e funções digestivas exclusivas do abomaso até que o rúmen esteja funcional (Cerdótes et al., 2004). O produto do rebanho de cria em bovinos de corte é o bezerro, e a produção de leite da mãe está relacionada ao desenvolvimento de sua cria, uma vez que maiores consumos de leite implicam maior ganho de peso à desmama (Albuquerque et al., 1993; Alencar et al., 1996). 
A produção de leite das vacas em pecuária extensiva está relacionada à quantidade e à qualidade da pastagem disponível, assim como às reservas nutricionais que conseguem armazenar. Portanto, há uma relação entre produção de leite e peso da vaca ao parto, que se intensifica quando conseguem manter ou até ganhar peso no período pré-parto (Vaccaro \& Dillard, 1966). Altas produções de leite, quando decorrentes da extensão do período lactacional, possuem relações negativas com o peso dos bezerros à desmama (Morris \& Wilton, 1986).

A época de nascimentos é um dos principais fatores que influenciam o peso ao nascer dos bezerros. Vacas com parição no início da primavera têm no terço final da gestação menor disponibilidade de pasto, de modo que os nutrientes obtidos são insuficientes para atender à demanda nutricional para o crescimento fetal, resultando em bezerros mais leves ao nascimento. Em animais manejados em campo nativo, a produção de leite é afetada pela época de parição, em razão da deficiência da produção de forragem no período hibernal das pastagens naturais, tipicamente de crescimento estival. Os pastos naturais param de crescer e crestam a partir das primeiras geadas que ocorrem no final do outono e se agravam no inverno, quando os pastos além de insuficientes, são pobres nutricionalmente, evidenciando que o efeito da época está intimamente relacionado com o estado das vacas (Bond \& Wiltbank, 1970). O genótipo e o sexo também influenciam o desempenho ponderal de bezerros, pois machos são maiores e mais pesados que as fêmeas e, os oriundos de cruzas manifestam sob efeito da heterose maior vigor geral e maior ganho (Pimentel et al., 2005).

Assim, o conhecimento da produção de leite e suas relações com o ganho de peso dos bezerros são de suma importância para melhor compreensão do período de lactação, época em que vacas e bezerros possuem maiores exigências nutricionais, e para determinar a eficiência produtiva do sistema de criação. O objetivo nesta pesquisa foi avaliar a disponibilidade de energia líquida no leite e o desempenho ponderal de bezerros do nascimento ao desmame criados em condições extensivas no Rio Grande do Sul.

\section{Material e Métodos}

O experimento foi conduzido em uma propriedade particular situada no município de Aceguá, que está localizado na região fisiográfica denominada Campanha, no Rio Grande do Sul. A precipitação anual média é de $1.350 \mathrm{~mm}$, variando entre 1.080 e $1.620 \mathrm{~mm}$. A distribuição média de chuvas durante o ano é de $34 \%$ no inverno, $25 \%$ na primavera, $16 \%$ no verão e $25 \%$ no outono (Macedo, 1984 ). A temperatura média anual é de $17,6^{\circ} \mathrm{C}$ : janeiro é o mês mais quente, com média é de $24^{\circ} \mathrm{C}$; e junho, o mais frio, com média de $12,5^{\circ} \mathrm{C}$, entretanto, podem ocorrer temperaturas extremas de -4 a $41^{\circ} \mathrm{C}$.

A fertilidade natural do solo é moderada, principalmente pelos baixos teores de fósforo. A cobertura natural do solo é superior a $80 \%$ sendo formada por vegetação nativa, apresentando variações qualitativas nos diferentes períodos do ano. Nos períodos de primavera e verão são baixos e densos, formando uma cobertura natural de boa qualidade para exploração sob pastejo. No período de inverno (junho a agosto), não apresentam crescimento e ficam secos pela ocorrência de geadas. A população de plantas predominante é a de gramíneas de ciclo estival, sendo formada principalmente pela grama-forquilha (Paspalum notadum) e grama-tapete (Axonopus affinis). As gramíneas de ciclo hibernal de maior ocorrência são as flexilhas (Stipa spp) e o azevém (Lolium multiflorum spp). A população de leguminosas de ciclo hibernal é, em sua maior parte, composta por trevo (Tripholium spp) (Pimentel, 2003).

A época de parição concentrou-se na primavera (setembro e outubro) e o desmame foi realizado conforme os bezerros apresentassem em média 189 dias de idade. Foi verificada lactação de 95 vacas de outubro de 2006 a maio de 2007, sendo 55 da raça Aberdeen Angus e 40 da raça Hereford, manejadas sob campo nativo respeitando a lotação de $0,7 \mathrm{UA} / \mathrm{ha}$ (UA $=$ unidade animal $=450 \mathrm{~kg}$ de peso vivo $)$. A produção de leite foi estimada pelo método pesagemmamada-pesagem (Pimentel et al., 2005). Os bezerros foram separados das vacas no dia anterior ao da pesagem (às $6 \mathrm{~h}$ ). Ao final da tarde (às $18 \mathrm{~h}$ ), eram colocados a mamar para fazer o esgotamento do úbere e mantidos separados das vacas por 12 horas. Na manhã seguinte, às $6 \mathrm{~h}$, os bezerros foram pesados em jejum e conduzidos junto as vacas para mamar entre 20 a 30 minutos. Após a amamentação os bezerros foram novamente pesados, sendo a diferença entre os pesos (peso ao final da mamada - peso em jejum) considerada a produção de leite em 12 horas, o qual multiplicado por dois, representou a estimativa de produção de leite/vaca durante 24 horas. Após a pesagem dos bezerros em jejum, as vacas foram pesadas individualmente em balança eletrônica.

As medidas de produção de leite e pesagem das vacas foram realizadas em intervalos de 21 dias. A produção de leite, nos períodos foi estimada pela equação proposta por Alencar etal. (1996): $\mathrm{PLn}=[(\operatorname{Ln}+\mathrm{Ln}-1) / 2] \times 21$, em que PLn = produção de leite do período de 21 dias; $\operatorname{Ln}=$ produção de leite estimada no dia, ou seja a produção 
observada no dia da pesagem multiplicada por dois e $\mathrm{n}=21$; $42 ;. . ., 189$. A produção de leite total (PLT) de cada vaca foi estimada somando-se todas as PLn $(\mathrm{PLT}=\Sigma \mathrm{PLn})$. O ganho médio diário (GMD) dos bezerros foi obtido a partir da seguinte fórmula utilizada pelo $\mathrm{PROMEBO}{ }^{\circledR}: \mathrm{GMD}=(\mathrm{PTnd}$ - PTP) $/ n^{\circ} d$, onde GMD é o ganho médio diário, PTnd é o peso dos bezerros aos " $n$ " dias de lactação iniciando com o peso ao parto $(\mathrm{P})$ e encerrando com o peso aos 189 dias ou peso à desmama ( $n=P, 21,42,63,84 \ldots, 189)$ e, "n ${ }^{\circ} d^{\prime}, o$ número de dias de intervalo entre os pesos.

Por meio de um pluviômetro, durante período experimental, eram registrados os valores das precipitações pluviais ( $\mathrm{mm}$ ). O pasto foi coletado nos potreiros onde ficavam os animais, conforme descrito por Silveira et al. (2005). As amostras de pasto foram levadas ao laboratório de Bromatologia da EMBRAPA Clima Temperado de Pelotas para análise dos percentuais de matéria seca (MS), matéria orgânica (MO), fibra detergente neutra (FDN), fibra em detergente ácido (FDA), nutrientes digestíveis totais (NDT), fibra bruta (FB), proteína bruta (PB), digestibilidade da matéria seca (DMS), energia digestível (ED) e energia metabolizável (EM). A média geral de cada um destes dados foi feita como análise.

$\mathrm{Na}$ análise dos dados, foram considerados fatores fixos a raça das vacas, o sexo dos bezerros, a ordem de parto, época de parição e prenhez. Como variáveis respostas, foram analisadas as produções de leite total, os pesos dos bezerros ao parto, peso dos bezerros nas pesagens e ao desmame, corrigido para 189 dias, a eficiência das vacas e o ganho médio diário de peso dos bezerros. A eficiência das vacas foi obtida a partir da fórmula utilizada pelo

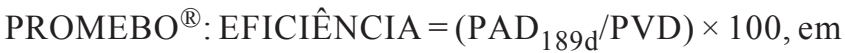
que $\mathrm{PAD}_{189 \mathrm{~d}}=$ peso dos bezerros ajustado aos 189 dias; $\mathrm{PVD}=$ peso das vacas ao desmame e multiplicado por 100 (resultado expresso em percentual). Os dados foram submetidos a ANOVA - GLM, no programa NCSS 7.0 (2007), considerando o seguinte modelo, descrito conforme a disponibilidade de informações.

$$
\mathrm{Y}_{\mathrm{jklmn}}=\mu+\mathrm{R}_{\mathrm{j}}+\mathrm{SB}_{\mathrm{k}}+\mathrm{OP}_{1}+\mathrm{E}_{\mathrm{m}}+\mathrm{P}_{\mathrm{n}}+\mathrm{e}_{\mathrm{jklmn}}
$$
em que: $Y_{j k l m n}=$ observação da produção de leite total, peso do bezerro ao parto, peso dos bezerros nas pesagens, peso do bezerro ao desmame, eficiência da vaca e ganho médio diário; $\mu=$ média geral; $\mathrm{R}_{\mathrm{j}}=$ efeito de raça $(\mathrm{j}=\mathrm{Aberdeen}$ Angus ou Hereford); $\mathrm{SB}_{\mathrm{k}}=$ efeito do sexo do bezerro $\left(\mathrm{k}=\right.$ macho ou fêmea); $\mathrm{OP}_{1}=$ efeito de ordem de parto $(1$ = primípara ou multípara $) ; \mathrm{E}_{\mathrm{m}}=$ efeito da época de parição $(\mathrm{m}=$ setembro ou outubro $) ; \mathrm{P}_{\mathrm{n}}=$ efeito da prenhez $(\mathrm{n}=$ gestante ou vazia $) ; \mathrm{e}, \mathrm{e}_{\mathrm{jklmn}}=$ erro experimental. Para relação entre peso do bezerro ao desmame ajustado aos 189 dias (variável dependente) e a produção total de leite (variável independente), utilizou-se análise de regressão no mesmo programa estatístico.

\section{Resultados e Discussão}

O desempenho dos bezerros (GMD) está relacionado aos níveis de exigências de energia líquida para mantença e ganho e a energia líquida disponível no leite para ganho de peso. O sistema para expressar as exigências de energia líquida (EL) para crescimento e terminação em bovinos de corte foi desenvolvido por Lofgreen \& Garrett (1968) e, sua utilização associada a escores de condição corporal e a produção de leite, segundo Bursinski et al. (1992), são formas indicadas para avaliar o aporte energético dos animais. Os resultados de produção de leite e desempenho dos bezerros neste estudo permitiram calcular, com base nos estudos de Robinson \& Yusuff (1978), a utilização e a disponibilidade de energia líquida do leite para os bezerros (Tabela 1).

A produção diária de leite atingiu o pico aos 63 dias de lactação, porém as exigências dos bezerros foram aumentando gradativamente após este período. Foram ainda necessários, em média, 6,92 $\mathrm{kg}$ de leite para cada $1 \mathrm{~kg}$ de peso ganho pelos bezerros ao final dos 189 dias. A eficiência na utilização do leite pelo bezerro é mais baixa no pico e aumenta à medida que transcorre a lactação. Esse resultado, assim como o relatado por Boggs et al. (1980), pode ser explicado pela complementação da dieta com a forragem de primavera e início de verão à qual os bezerros foram submetidos. Além disso, com o passar do tempo, os bezerros passam a buscar outras fontes de alimento que não o leite materno.

A cada $10 \mathrm{~kg}$ a mais de leite produzido em 189 dias de lactação, houve um aumento de $0,4 \mathrm{~kg}$ no peso dos bezerros ao desmame (Figura 1). Todavia, a produção total de leite explica apenas $26 \%$ do peso dos bezerros ao desmame. Os $74 \%$ restantes do peso dos bezerros ao final dos 189 dias de lactação podem ser explicados pela época de nascimento dos mesmos, a qual coincide com o início da primavera, período que favorece as pastagens naturais que serviram de alimento aos bezerros. Resultados similares foram obtidos por Robinson et al. (1978) em estudo da lactação de vacas Hereford com metodologia semelhante.

Outro ponto importante a ser considerado é a energia líquida para ganho disponível no leite. Pimentel et al. (2003)

\footnotetext{
${ }^{\circledR}$ Programa de melhoramento de bovinos de carne.
} 
Tabela 1 - Energia líquida para manença e ganho e energia disponível no leite para bezerros aos 189 dias

\begin{tabular}{|c|c|c|c|c|c|c|c|c|}
\hline \multirow[t]{2}{*}{ Dias de lactação } & \multirow[t]{2}{*}{$\begin{array}{l}\text { Peso vivo dos } \\
\text { bezerros }(\mathrm{kg})\end{array}$} & \multirow[t]{2}{*}{$\begin{array}{c}\text { Produção de leite } \\
\text { das vacas }(\mathrm{kg})\end{array}$} & \multirow[t]{2}{*}{$\begin{array}{c}\text { Ganho médio } \\
(\mathrm{kg} / \mathrm{dia})\end{array}$} & \multirow[t]{2}{*}{$\begin{array}{c}\text { Leite/ } \\
\text { ganho }(\mathrm{kg})\end{array}$} & \multicolumn{2}{|c|}{$\begin{array}{c}\text { Exigências de } \\
\text { energia líquida }(\mathrm{Mcal})\end{array}$} & \multicolumn{2}{|c|}{$\begin{array}{l}\text { Energia líquida para } \\
\text { ganho disponível no leite }\end{array}$} \\
\hline & & & & & Para mantença & Para ganho & Mcal & $\%$ \\
\hline 21 & 63,55 & 6,65 & 1,20 & 5,54 & 1,73 & 1,65 & 1,98 & 120,40 \\
\hline 42 & 77,86 & 7,01 & 1,04 & 6,75 & 2,02 & 1,63 & 2,48 & 152,20 \\
\hline 63 & 94,44 & 8,24 & 0,82 & 10,04 & 2,33 & 1,45 & 3,54 & 244,12 \\
\hline 84 & 112,87 & 4,79 & 0,75 & 6,43 & 2,67 & 1,49 & 1,87 & 125,55 \\
\hline 105 & 129,46 & 6,09 & 0,75 & 8,17 & 2,96 & 1,65 & 2,99 & 180,46 \\
\hline 126 & 146,09 & 6,57 & 0,76 & 8,59 & 3,24 & 1,86 & 3,63 & 195,31 \\
\hline 147 & 157,46 & 5,57 & 0,76 & 7,30 & 3,42 & 1,97 & 3,04 & 154,43 \\
\hline 168 & 169,36 & 4,73 & 0,75 & 6,32 & 3,61 & 2,03 & 2,49 & 122,51 \\
\hline 189 & 191,14 & 2,64 & 0,71 & 3,71 & 3,96 & 2,11 & 0,77 & 36,48 \\
\hline
\end{tabular}

Médias ajustadas a cada 21 dias para peso vivo dos bezerros, produção de leite das vacas e ganho médio diário dos bezerros.

Exigências de energia líquida para mantença e ganho dos bezerros, com base em seus respectivos pesos, ganhos e consumo de leite calculados pelas fórmulas e valores obtidos do Nutrient Requirements of Beef Cattle (NRC, 1970, 1996).

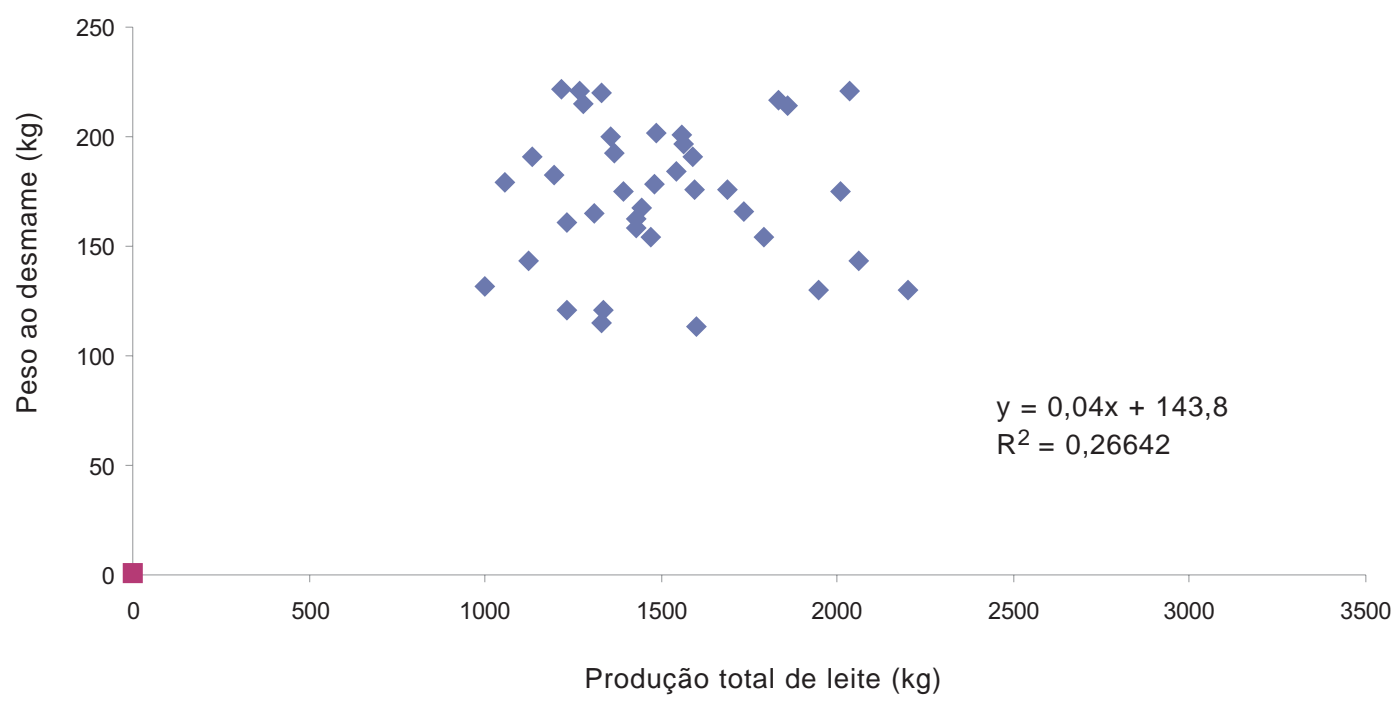

Figura 1 - Regressão linear do peso ao desmame ajustado aos 189 dias relacionado à produção total de leite.

Tabela 2 - Componentes da pastagem nativa e índice de chuvas durante o período experimental

\begin{tabular}{|c|c|c|c|c|c|c|c|}
\hline \multirow[t]{2}{*}{ Item } & \multicolumn{6}{|c|}{ Mês } & \multirow[t]{2}{*}{ Média } \\
\hline & Novembro & Dezembro & Janeiro & Fevereiro & Março & Abril & \\
\hline Matéria seca (\%) & 40,5 & 42,9 & 36,7 & 44,6 & 50,0 & 94,7 & 51,6 \\
\hline Matéria orgânica (\%) & 88,9 & 86,7 & 86,9 & 88,3 & 89,5 & 88,5 & 88,1 \\
\hline Fibra em detergenteneutro (\%) & 56,1 & 64,8 & 57,7 & 69,4 & 72,5 & 64,7 & 64,2 \\
\hline Fibra em detergenteácido (\%) & 38,0 & 37,1 & 35,8 & 41,4 & 42,0 & 42,7 & 39,5 \\
\hline Nutrientes digestíveistotais $(\%)$ & 65,8 & 70,3 & 72,4 & 65,4 & 67,1 & 62,8 & 67,3 \\
\hline Fibra bruta $(\%)$ & 31,6 & 30,8 & 29,7 & 34,4 & 33,2 & 35,5 & 32,5 \\
\hline Proteína bruta $(\%)$ & 11,9 & 11,9 & 13,0 & 9,7 & 9,8 & 10,1 & 11,1 \\
\hline Digestibilidadede matéria seca (\%) & 63,9 & 68,5 & 71,0 & 63,5 & 65,1 & 60,5 & 65,4 \\
\hline Energia digestível $(\%)$ & 3,1 & 3,4 & 3,6 & 3,1 & 3,2 & 2,9 & 3,2 \\
\hline Energia metabolizável (\%) & 2,6 & 3,1 & 3,2 & 2,7 & 2,8 & 2,5 & 2,8 \\
\hline Chuvas $(\mathrm{mm})$ & 110 & 142 & 110 & 144 & 222 & 142 & 145 \\
\hline
\end{tabular}

Letras diferentes na coluna dentro de fatores indicam médias diferentes $(\mathrm{P}<0,05)$. 
e Robinson et al. (1978) relataram que a disponibilidade de energia líquida para ganho no leite se mantém positiva até o quarto mês de lactação, atendendo às exigências de mantença com sobra para ganho, e que, a partir do quinto mês, a energia líquida para ganho no leite assume valores negativos. Esses autores trabalharam na mesma região geográfica e em condições experimentais semelhantes. Entretanto, Robinson et al. (1978) esclareceu que houve um período de seca prolongada e esse é um fator importante. Os resultados deste estudo não confirmaram os achados de Robinson et al. (1978), visto que até os 168 dias de lactação houve sobra de energia líquida disponível no leite. No pico lactacional, a sobra de energia chegou a $144,12 \%$, ou seja, nesse período havia energia líquida disponível no leite suficiente para atender às necessidades energéticas de mais 1,5 bezerro. No último período avaliado, a energia líquida para ganho disponível no leite supriu apenas $36,48 \%$ das necessidades de ganho, ao passo que, nessa época, para que houvesse ganho de peso, foi necessário utilizar dos nutrientes do pasto. Mesmo assim, em momento algum ocorreu déficit de energia para ganho disponível no leite.

Assim como neste estudo, Cerdótes et al. (2004) fizeram uma avaliação de pasto durante seis meses e encontraram valores semelhantes aos deste para matéria seca e fibra detergente neutra; no entanto, encontraram para proteína bruta 5,64\%, inferior ao deste ensaio de $11,1 \%$ na média dos seis meses de avaliação. Essa diferença pode estar relacionada, entre outros fatores, ao local onde foram realizadas as pesquisas, e ainda, ao ano e às suas condições temporais. Segundo Pimentel et al. (2005), a variabilidade forrageira está relacionadas às diferenças nas regiões geográficas, assim como aos tipo de solo e ao clima. De maneira geral, os dados quantitativos da pastagem natural foram similares aos obtidos por Cerdótes et al. (2004), que encontraram médias de $46,17 \%$ para matéria seca e $71,59 \%$ para fibra em detergente neutro.

Os bezerros das vacas Aberdeen Angus foram mais pesados que os das Herford $(\mathrm{P}<0,05)$ dos 84 aos 189 dias da lactação e também à desmama, mas, no período do nascimento até os 63 dias de lactação, os pesos foram similares $(\mathrm{P}>0,05)$ entre os dois genótipos (Tabela 3). As vacas Hereford foram menos eficientes que as Aberdeen Angus, o que já era esperado, em razão do ganho médio diário dos bezerros $(\mathrm{P}<0,05)$, uma vez que os da raça Aberdeen Angus ganharam mais peso em comparação aos da raça Hereford.

Os bezerros Aberdeen Angus foram mais pesados ao desmame que os da raça Hereford, provavelmente em decorrência da época de parição das vacas, pois os bezerros Aberdeen Angus nasceram mais cedo que os Hereford. Até o pico lactacional, não foram encontradas diferenças no

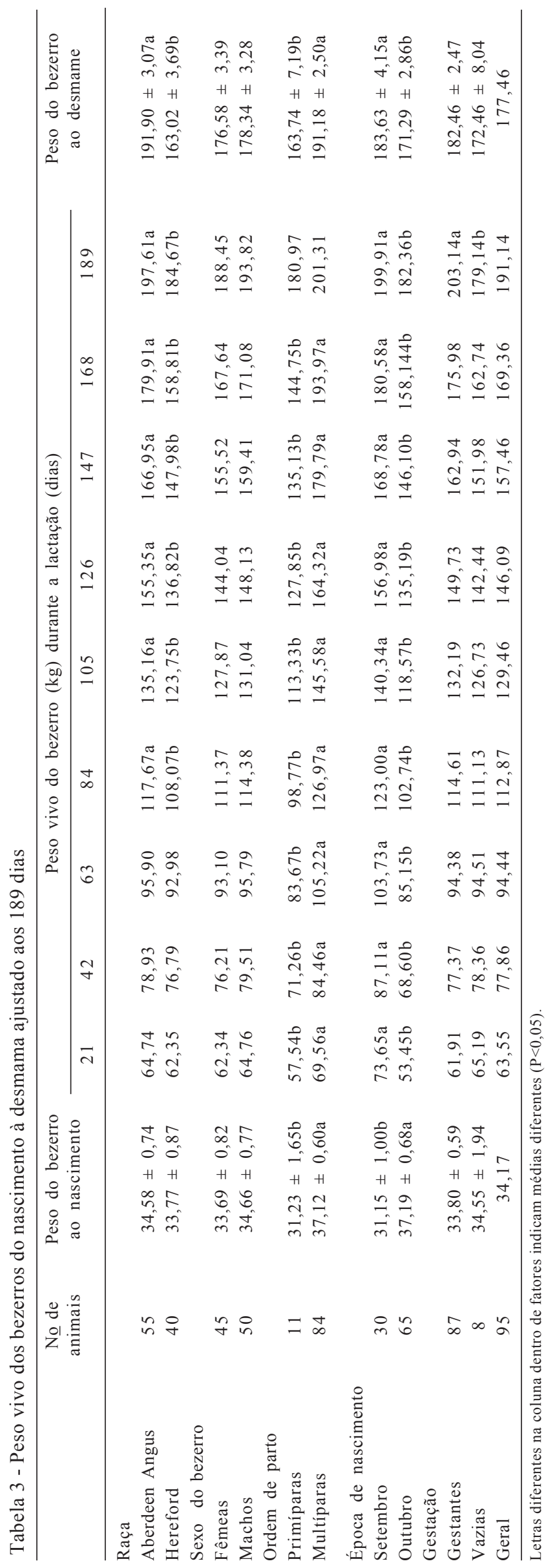

R. Bras. Zootec., v.39, n.11, p.2545-2552, 2010 
peso dos bezerros entre os genótipos, presumivelmente em virtude da homogeneidade das amostras. Klept et al. (1965), estudando a lactação de vacas de corte, encontraram correlações significativas entre o peso dos bezerros e a produção de leite em animais da raça Aberdeen Angus, no entanto, essas correlações não foram significativas para Hereford, demonstrando diferença entre raças na quantidade de leite produzida.

De acordo com Albuquerque et al. (1993), o efeito significativo do genótipo sobre a produção de leite indica a existência de uma variação genética para essa característica, a qual pode ser controlada por vários fatores, como a conversão alimentar, a capacidade de busca do alimento e a resistência ao calor.

Quando considerada a ordem de parto, os bezerros filhos de vacas multíparas foram mais pesados ao nascimento $(\mathrm{P}=0,002213)$ e à desmama $(\mathrm{P}=0,001018)$ se comparados aos filhos de vacas primíparas, com ganho diário médio de $0,81 \pm 0,01 \mathrm{~kg} / \mathrm{dia}$ e $0,62 \pm 0,04 \mathrm{~kg} / \mathrm{dia}$, respectivamente. Além disso, os filhos de vacas multíparas demonstraram superioridade no peso dos 21 aos 168 dias pós-parto $(\mathrm{P}<0,05)$. Assim como neste trabalho, outros autores (Rutledge, et al., 1971; Boggs, et al., 1980) também têm observado influência da ordem de parto no peso dos bezerros ao desmame e fatores de correção para esse efeito são geralmente usados.

A significância da ordem de parto na produção de leite foi relatada por Neville et al. (1974), que demonstraram a importância do uso de um fator de correção para idade da vaca para produção de leite para que ocorra apropriada evolução de vacas de corte e seus bezerros. Boggs et al. (1980) estudaram os efeitos do leite e da forragem no desempenho de bezerros e afirmaram que vacas com 4, 5 e 8 anos de idade produziram mais leite que aquelas com menos de 4 e com mais de 8 anos $(\mathrm{P}<0,05)$. Já Rutledge et al. (1971) relataram que a idade das vacas não influenciou o peso dos bezerros ao desmame, mas afetou variáveis como peso das vacas, peso dos bezerros ao nascer e produção de leite. Williams et al. (1979) estudaram a produção de leite em vacas Hereford e observaram que a idade da vaca interfere no ganho médio diário dos bezerros, uma vez que bezerros filhos de vacas com 2 anos de idade ganharam $0,42 \mathrm{~kg}$, com 3 anos $0,50 \mathrm{~kg}$ e, os filhos das mais maduras ganharam $0,68 \mathrm{~kg}$.

A época de nascimento dos bezerros influenciou $(\mathrm{P}<0,05)$ a produção de leite total (Tabela 4$)$. Vacas que pariram em setembro produziram $1605,04 \pm 62,09 \mathrm{~kg}$ de leite e as que pariram em outubro produziram $1378,78 \pm 49,60 \mathrm{~kg}$ de leite. Desse modo, a época de nascimento influenciou $(\mathrm{P}<0,05)$ o peso dos bezerros do nascimento até a desmama, de modo que aqueles nascidos em outubro $(37,19 \pm 0,68 \mathrm{~kg})$ foram mais pesados que os nascidos em setembro $(31,15 \pm$ $1,00 \mathrm{~kg}$ ), entretanto os de setembro passaram a ser mais pesados dos 21 dias de lactação vida até o desmame.

O ganho médio diário apresentou diferenças $(\mathrm{P}=0,004)$ entre as épocas de nascimento. Os bezerros que nasceram em setembro (época 1) apresentaram ganho de 0,76 $\pm 0,02$ $\mathrm{kg} /$ dia e os nascidos em outubro (época 2) ganho de 0,67 \pm $0,02 \mathrm{~kg} / \mathrm{dia}$. Esses resultados corroboram os encontrados por Pimentel (2003) em estudo com metodologia semelhantes em local de mesmas condições climáticas.

Neste estudo, o sexo dos bezerros não influiu na produção de leite total $(\mathrm{P}>0,05)$, resultado que confirma o relato de Franzo et al. (2001), que estudaram o efeito do sexo de bezerros sobre as produções de leite de vacas Hereford.

Tabela 4 - Médias ajustadas para ganho diário médio dos bezerros, eficiência das vacas e produção total leite

\begin{tabular}{|c|c|c|c|c|}
\hline Fator & № de animais & Ganho médio diário (kg/dia) & Eficiência $(\%)$ & Produção de leite total $(\mathrm{kg})$ \\
\hline \multicolumn{5}{|l|}{ Raça da vaca } \\
\hline Aberdeen Angus & 55 & $0,78 \pm 0,02 \mathrm{a}$ & $45,24 \pm 0,72 \mathrm{a}$ & $1458,12 \pm 45,85$ \\
\hline Hereford & 40 & $0,64 \pm 0,02 b$ & $39,40 \pm 0,86 b$ & $1525,69 \pm 72,50$ \\
\hline \multicolumn{5}{|l|}{ Sexo dos bezerros } \\
\hline Fêmeas & 45 & $0,71 \pm 0,02$ & $41,70 \pm 0,79$ & $1429,48 \pm 55,16$ \\
\hline Machos & 50 & $0,71 \pm 0,02$ & $42,95 \pm 0,77$ & $1554,33 \pm 54,45$ \\
\hline \multicolumn{5}{|l|}{ Ordem de parto } \\
\hline Primíparas & 11 & $0,62 \pm 0,04 b$ & $42,34 \pm 1,69$ & $1631,46 \pm 240,46$ \\
\hline Multíparas & 84 & $0,81 \pm 0,01 \mathrm{a}$ & $42,30 \pm 0,59$ & $1352,36 \pm 39,27$ \\
\hline \multicolumn{5}{|c|}{ Época do nascimento } \\
\hline Setembro & 30 & $0,76 \pm 0,02 \mathrm{a}$ & $43,52 \pm 0,97$ & $1605,04 \pm 62,09 a$ \\
\hline Outubro & 65 & $0,67 \pm 0,02 b$ & $41,13 \pm 0,67$ & $1378,78 \pm 49,60 b$ \\
\hline \multicolumn{5}{|l|}{ Gestação } \\
\hline Gestantes & 87 & $0,74 \pm 0,01$ & $41,85 \pm 0,58$ & $1628,26 \pm 40,64$ \\
\hline Vazias & 8 & $0,68 \pm 0,05$ & $42,79 \pm 1,88$ & $1355,55 \pm 128,53$ \\
\hline Geral & 95 & 0,71 & 42,32 & 1491,91 \\
\hline
\end{tabular}

Letras diferentes na coluna dentro de fatores indicam médias diferentes $(\mathrm{P}<0,05)$. 
Esse efeito também não interferiu $(\mathrm{P}>0,05)$ na eficiência individual das vacas (\%) nem no desempenho dos bezerros. O efeito do sexo dos bezerros sobre a produção de leite é uma questão muito discutida. Outros autores (Reynold et al., 1978; Chenette \& Frham, 1981; Daley et al., 1987) relataram pequeno ou nenhum efeito do sexo do bezerro sobre a produção de leite da mãe, enquanto Keller (1980) e McCuskey et al. (1986) encontraram maiores produções para vacas que amamentavam machos, provavelmente pelo maior estímulo que bezerros machos provocam em suas mães, devido à maior voracidade no momento de amamentação. Melton et al. (1967) verificaram que bezerros machos mamam maior quantidade e mais frequentemente que as fêmeas no início da lactação e que essa diferença entre os sexos se reduzia com o decorrer do tempo. Segundo Robinson et al. (1978), a produção de leite parece ser mais influenciada pelo tamanho do bezerro que pelo sexo. Rutledge et al. (1971) e Alencar et al (1985) também encontraram efeitos lineares significativos do peso do bezerro ao nascer sobre a produção total de leite das vacas e concluíram que bezerros mais pesados ao nascimento consumiram mais leite ou apresentaram maior capacidade de consumo, ou alguma relação com a produção de hormônios envolvidos na lactação.

A placenta da vaca secreta o hormônio lactogênico, que pode influenciar a produção de leite da vaca na lactação subsequente. Quanto maior o feto, maior o tamanho da placenta e maior secreção de hormônios (Chew et al., 1981; Mallinckrodt et al., 1993). Martson et al. (1992) encontraram maior produção de leite em vacas da raça Aberdeen Angus que amamentavam fêmeas, mas, em vacas da raça Simental, observaram que a maior produção foi para aquelas que amamentavam machos.

A prenhez não interferiu $(\mathrm{P}>0,05)$ na produção de leite total $(\mathrm{kg})$ nem na eficiência das vacas (\%) ou no desempenho dos bezerros (kg). Pimentel et al. (2005) estudaram a produção de leite e o desempenho pós-parto em vacas Hereford e não notaram diferenças entre vacas gestantes e vazias no peso dos bezerros ao desmame, no pico lactacional, na produção de leite total e na persistência de lactação. A lactose é o carboidrato disponível mais importante para o bezerro e está diretamente relacionada ao volume de leite produzido por ser um dissacarídeo hidrofílico (ABLV, 2008).

\section{Conclusões}

Em condições extensivas de criação de bovinos de corte na região da Campanha do Rio Grande do Sul, o desempenho ponderal dos bezerros até seis meses de vida está fortemente relacionado à energia líquida disponível no leite.

\section{Referências}

ASSOCIAÇÃO BRASILEIRA DE LEITE LONGA VIDA - ABLV. Site informativo. Disponível em: <http://www.ablv.org.br/Index.cfm> Acesso em: 2/12/2007.

ALBUQUERQUE, L.G.; ELER, J.D.; PARANHUS, M.J.R.C. Produção de leite de vacas da raça Canchim. Revista da Sociedade Brasileira de Zootecnia, v.22, n.5, p.745-755, 1993.

ALENCAR, M.M.; JUNQUEIRA FILHO, A.A.; PARANHUS, N.E. Produção de leite de vacas da raça Canchim. Revista Brasileira de Zootecnia, v.14, n.3, p.358-366,1985.

ALENCAR, M.M. Herdabilidade e efeito da produção de leite sobre a eficiência reprodutiva de vacas da raça Canchim. Revista da Sociedade Brasileira de Zootecnia, v.16, n.2, p.163-169, 1987.

ALENCAR, M.M.; TULLIO, R.R.; CRUZ, G.M. et al. Produção de leite da vaca e desenvolvimento do bezerro em gado de corte. Revista da Sociedade Brasileira de Zootecnia, v.25, n.1, p.92-101, 1996.

BARCELLOS, J.O.J.; LOBATO, J.F.P. Efeitos da época no nascimento de bezerros Hereford e suas cruzas II. Pesos ao desmame, ano e sobreano. Revista da Sociedade Brasileira de Zootecnia, v.21, n.1, p.150-157, 1992.

BARTLE, S.J.; MALES, J.R.; PRESTON, R.L. Effect of energy intake on the postpartum interval in beef cows and the adequacy of the cow's milk production for calf growth. Journal Animal Science, v.58, n.5, p.1068-1074, 1984.

BEAL, W.E.; NOTTER, D.R.; AKERS, R.M. et al. Techniques for estimation of milk yield in beef cows and relationships of milk yield to calf weight gain and postpartum reproduction. Journal Animal Science, v.68, n.3, p.937-943, 1990.

BOGGS, D.L.; SMITH, E.F.; SCHALLES, R.R. et al. Effects of milk and forage intake on calf performance. Journal of Animal Science, v.51, n.3, p.550-553, 1980.

BOND, J.; WILTBANK, J.N. Effect of energy and protein on estrus conception rate, growth and milk production of beef females Journal of Animal Science, v.30, p.438-444, 1970.

BUSKIRK, D.D.; LEMANAGER, R.P.; HORSTMAN, L.A. Estimation of net energy requirements $\left(\mathrm{NE}_{\mathrm{m}}\right.$ and $\left.\mathrm{NE}_{\ddot{\mathrm{A}}}\right)$ of lacting beef cows. Journal of Animal Science, v.70, n.2, p.3867-3876, 1992.

CACHAPUZ, J.M.S. Alternativas para aumentar a produção de terneiros. 2.ed. Porto Alegre: EMATER-RS, 1985. 16p.

CAMPOS, L. Manual do Programa de Melhoramento de Bovinos de Carne - PROMEBO. Disponível em: <http:// www.promebo.com.br/ Manual.pdf> Acesso em: 25/8/2009.

CERDÓtes, L.; RESTle, J.; FILHO, D.C.A. et al. Produção e composição do leite de vacas de quatro grupos genéticos submetidas a dois manejos alimentares no período de lactação. Revista Brasileira de Zootecnia, v.33, n.3, p.610-622, 2004.

CHENETTE, C.G.; FRAHM, R.R. Yield and composition of milk from various two-breed cross cows. Journal of Animal Science, v.52, n.3, p.483-493, 1981.

CHEW, B.P.; MAIER, L.C.; HILLERS, J.K. et al. Relationship calf birth weight and dam's subsequent 200 and 305 day yields of milk, fat and total solids in Holsteins. Journal of Dairy Science, v.64, n.12, p.2401-2408, 1981.

CHURCH, D.C. Digestive physiology and nutrition of ruminants Corvallis: O \& B Books, 1979. 350p.

CUNDIFF, L.V.; GREGORY, K.E.; SCHWULST, F.J. et al. Effects of heterosis on maternal performance and milk production in Hereford, Angus and Shorthorn cattle. Journal of Animal Science, v.38, n.3, p.728-745, 1974.

DALEY, D.R.; MCCUSKEY, A.; BAILEY, C.M. Composition and yield of milk from beef-type Bos taurus and Bos indicus x Bos taurus dams. Journal of Animal Science, v.64, n.1, p.373-384, 1987.

FORSTER, K.M.; PIMENTEL, M.A.; MORAES, J.C.F. Milk production in beef cattle 21 . Weight performance of hereford and aberdeen angus lactation. In: NUTRITIONAL 
BIOTECHNOLOGY IN THE FEED AND FOOD INDUSTRIES ALLTECH'S ANNUAL SYMPOSIUM, 24., 2008, Lexington. Anais... Kentucky: Alltech, [2008]. p.70-71.

FRANZZO, V.; PIMENTEL, M.A.; JARDIM, P.O.C. et al. Efeito do peso ao parto sobre a produção de leite e eficiência individual em novilhas primíparas Hereford e cruzas. Revista Brasileira de Agrociência, v.7, n.3, p.163-236, 2001

FREDEEN, H.T.; WEISS, G.M.; RAHNEFELD, G.W. et al. Genotype $x$ environment interactions for milk production and other biological traits with production efficiency to weaning. Canadian Journal of Animal Science, v.68, n.2, p.619, 1988

GREEN, R.D.; CUNDIFF, L.V.; DICKERSON, G.E. et al. Output/ input differences among nonpregnant, lactating Bos indicus Bos taurus and Bos taurus - Bos taurus F1 cross cows. Journal of Animal Science, v.69, n.3, p.3156-3166, 1991

HOLLOWAY, J.W.; STEPHENS, D.F.; WHITEMAN, J.V. et al. Performance of 3-year old Hereford, Hereford $\times$ Holstein and Holstein cows on range and in drylot. Journal of Animal Science, v.40, n.1, p.114-125, 1975

JEFFERY, N.B.; BERG, R.T.; HARDIN, R.T. Factors influencing milk yield of beef cattle. Canadian Journal of Animal Science, v.51, n.3, p.551-560, 1971.

JENKINS, T.G.; FERREL, C.L. Lactation characteristics of nine breeds of cattle fed various quantities of dietary energy. Journal of Animal Science, v.70, n.2, p.1652-1660, 1992.

KELLER, D.G. Milk production in Cattalo cows and its influence on calf gains. Canadian Journal of Animal Science, v.60, n.1, p.19, 1980 .

KLEPT, R.H.; MASON, T.R.; RIGGS, J.K. Milk production of beef cows and its relationship to the weaning weight of their calves. Journal of Animal Science, v.24, n.2, p.286 (Abst.), 1965.

LOFGREEN, G.P.; GARRETT, W.N. Asystem for expressing net energy requirements and feed values for growing and finishing beef cattle. Journal of Animal Science, v.27, n.3, p.793-806, 1968

MACEDO, W. Levantamento de reconhecimento dos solos do município de Bagé, RS. Bagé: EMBRAPA, 1984. 69p.

MALLINCKRODT, C.H.; BOURDON, R.M.; GOLDEN, B.L. et al. Relationship of maternal milk expected progeny differences to actual milk yield and calf weaning weight. Journal of Animal Science, v.71, n.1, p.355-362, 1993

MARSTON, T.T.; SIMMS, D.D.; SHALLES, R.R. et al. Relationship of milk production, milk expected progeny difference, and calf weaning weight in Angus and Simental cow-calf pairs. Journal of Animal Science, v.70, n.2, p.3304-3310, 1992

McCUSKEY, A.; DALEY, D.R.; BAILEY, C.M. Milk yield of beeftype Bos Taurus $\times$ Bos indicus dams. Journal of Animal Science, v.63, p.177 (Abstr.), 1986

MELTON, A.A.; RIGGS, J.K.; NELSON, L.A. Milk production, composition and calf gains of Angus, Charoles and Hereford cows. Journal of Animal Science, v.26, n.4, p.804-809, 1967.

MENDONÇA, G.; PIMENTEL, M.A.; CARDELLINO, R.A. et al. Época de nascimento, genótipo, e sexo de terneiros cruzas taurinos e zebuínos sobre o peso ao nascer, à desmama e eficiência individual de primíparas Hereford. Ciência Rural, v.33, n.6, p.1117-1121, 2003.

MORRIS, M.R.; WILTON, J.W. Breeding system, cow weight and milk yield effects on various biological variables in beef production. Journal of Animal Science, v.63, n.2, p.1361-1372, 1986.

NCSS 7.0. Statistical System for Windows - User's guide I, II, III. Kaysville, Utah, 2007
NEVILLE, J.R.; WARREN, E.P.; GRIFFEY, W.A. Estimates of age effect on milk production in Hereford cows. Journal of Animal Science, v.38, n.1, p.1-10, 1974.

NOTTER, D.R.; CUNDIFF, L.V.; SMITH, G.M. et al. Characterization of biological types of cattle VII. Milk production in young cows and transmitted maternal effects on preweaning growth of progeny. Journal of Animal Science, v.46, n.4, p.908-921, 1978.

NATIONAL RESEARCH COUNCIL - NRC. Nutrient requirements of beef cattle. Washington, D.C.: National Academy Press, 1970 $77 \mathrm{p}$.

NATIONAL RESEARCH COUNCIL - NRC. Nutrient requirements of beef cattle. 7.ed. Washington, D.C.: National Academy Press, 1996. $241 \mathrm{p}$

PIMENTEL, M.A.; MORAES, J.C.F.; JAUME, C.M. et al. Produção de leite e desempenho pós-parto de vacas Hereford em distintas condições reprodutivas criadas extensivamente. Ciência Rural, v.35, n.1, p.150-156, 2005

PIMENTEL, M.A.; MORAES, J.C.F.; JAUME, C.M. et al. Características da lactação de vacas Hereford criadas em um sistema de produção extensivo na região da campanha do Rio Grande do Sul. Revista Brasileira de Zootecnia, v.35, n.1, p.159-168, 2006.

PIMENTEL, M.A.; FORSTER, K.M.; BRAUNER, C.C. et al. Produção de leite em bovinos de corte 16. Desempenho ponderal de terneiros do nascimento aos 126 dias de lactação. In: REUNIÃO ANUAL DA SOCIEDADE BRASILEIRA DE ZOOTECNIA, 44., 2007, Jaboticabal. Anais... São Paulo: Sociedade Brasileira de Zootecnia/ Gmosis, [2007] (CD-ROM)

REYNOLDS, W.S.; DE ROUEN, T.M.; BELLOWS, R.A. Relationship of milk yield of dam to early growth rate of strainghtbres and crossbred calves. Journal of Animal Science, v.47, n.3, p.584-594, 1978.

RIBEIRO, A.M.L.; LOBATO, J.F.P. Produtividade e eficiência reprodutiva de três grupos raciais de novilhas de corte II. Desenvolvimento da progênie até o desmame reprodutivo das novilhas. Revista Brasileira de Zootecnia, v.17, n.6, p.508-515, 1998.

ROBINSON, O.W.; YUSUFF, M.K.M. Milk production in Hereford cows. I. Means and correlations. Journal of Animal Science, v.47, n.1, p.131-136, 1978

ROVIRA, J. Reprodución y manejo de los rodeos de cría Montevideo: Hemisfério Sur, 1974. 296p.

ROVIRA, J. Reprodución y manejo de los rodeos de cría en pastoreo. Montevideo: Hemisfério Sur, 1996. 288p.

RUTLEDGE, J.J.; ROBISON, O.W.; AHLSCHWEDE, W.T. et al. Milk yield and its influence on 205-day weight of beef calves. Journal of Animal Science, v.33, n.3, p.563-567, 1971.

SCHWULST, F.J.; KOCK, R.M.; GREGORY, K.E. Heterosis of milk producton in beef cows. Journal of Animal Science, v. 27 p.1129, 1968 (Abstr.).

SILVEIRA, V.C.P.; VARGAS, A.F.C.; OLIVEIRA, J.O.R. et al. Qualidade de pastagem obtida por diferentes métodos de amostragem e em diferentes solos na Apa do Ibirapuitã, Brasil. Ciência Rural, v. 35, n. 3, p. $582-588,2005$

VACCARO, R.; DILLARD, E.U. Relationship among dam's weight changes to calf's growth rate in Hereford cattle. Journal of Animal Science, v.25, n.3, p.1063-1068, 1966.

WILLIAMS, J.H.; ANDERSON, D.C.; KRESS, D.D. Milk production in Hereford cattle. I. Effects of separation interval on weightsuckle-weight milk production estimates. Journal of Animal Science, v.49, n.6, p.1438-1442, 1979. 